\title{
Spectrum of Filamentous Fungi from Sputum of Tuberculosis Relapse and Retreatment Patients in Tuberculosis Reference Facilities
}

\author{
Josephat Tonui $^{*}$, Marianne Mureithi' ${ }^{1}$, Walter Jaoko ${ }^{1}$, Christine Bii ${ }^{2}$ \\ ${ }^{1}$ Department of Medical Microbiology, School of Medicine, University of Nairobi, Nairobi, Kenya \\ ${ }^{2}$ Kenya Medical Research Institute, Centre for Microbiology Research, Mycology Unit, Nairobi, Kenya \\ Email: ^kipjoston@gmail.com, ^jtonui@students.uonbi.ac.ke
}

How to cite this paper: Tonui, J., Mureithi, M., Jaoko, W. and Bii, C. (2020) Spectrum of Filamentous Fungi from Sputum of Tuberculosis Relapse and Retreatment Patients in Tuberculosis Reference Facilities. Open Journal of Medical Microbiology, 10, 190-203.

https://doi.org/10.4236/ojmm.2020.104017

Received: November 23, 2019

Accepted: December 6, 2020

Published: December 9, 2020

Copyright $\odot 2020$ by author(s) and Scientific Research Publishing Inc. This work is licensed under the Creative Commons Attribution International License (CC BY 4.0).

http://creativecommons.org/licenses/by/4.0/

(c) (i) Open Access

\begin{abstract}
Background: Fungal infections represent a significant cause of morbidity and mortality among immunocompromised individuals. Pulmonary fungal infection may be missed or misdiagnosed as tuberculosis (TB) hence complicating management of these patients. The current study reports the spectrum of filamentous fungi isolated from sputum of TB relapse and retreatment cases at selected reference facilities in Kenya. Methods: A total of 340 sputum samples collected during the period of June 2018 to June 2019 were subjected to mycological investigations. The samples were mucolysed and inoculated on sabourauds dextrose agar (SDA) and incubated at $30^{\circ} \mathrm{C}$ for 7 days and checked daily for fungal growth. Moulds were identified by macroscopic and microscopic morphological features and the species were confirmed by sequencing. Results: The diversity of fungi out of the 340 sputum samples analyzed was as follows; $16 \%(\mathrm{n}=53)$ were positive for moulds with Aspergillus species being the predominant constituting $68 \%(\mathrm{n}=36)$. Among the Aspergilli, A. flavus and $A$. niger were the most frequently isolated adding up to $23 \%,(\mathrm{n}=12)$ and $15 \%(\mathrm{n}=8)$ respectively. Additionally, Paecillomyces variotii $(9 \%, \mathrm{n}=5)$, Scedosporium aspiospermum $(6 \%, \mathrm{n}=3)$, Mucor racemosus $(8 \%, \mathrm{n}=4)$ and Penicillium spp. $(9 \%, \mathrm{n}=5)$ were also recovered. Conclusion: The isolated fungi represented potential respiratory pathogens that could be responsible for persistent TB like symptoms despite treatment that could be misdiagnosed as relapse requiring treatment. Fungal investigation of all presumptive $\mathrm{TB}$ relapse cases should be advocated before treatment. This will reduce unnecessary retreatment, delayed antifungal intervention and unwarranted morbidity and mortality associated with misdiagnosis.
\end{abstract}

\section{Keywords}

Filamentous Fungi, Tuberculosis, Relapse, Retreatment, Spectrum 


\section{Introduction}

Fungi are emerging significant pathogens mainly as opportunist in individuals with impaired immunity; particularly in people living with HIV, diabetes, cancer as well as those treated with toxic chemotherapy [1]. Certain species of fungi are also capable of invading and causing disease in immunocompetent individuals. The increase in incidence of fungal infections has been exacerbated by the escalation of immune debilitating conditions such as HIV [2]. Tuberculosis (TB) remains a significant public health threat in Kenya and the country is listed among the 30 high burden countries [3]. A prevalence survey that was carried out in 2016 confirmed that Kenya's TB burden is higher than previously estimated. The highest burden was recorded in young men of the reproductive age group 25 - 34 years [4]. Fungal spores being ubiquitous can colonize pre-existing $\mathrm{TB}$ cavities in the lungs. Tuberculosis retreatment cases respond poorly to anti TB medication and it is thought that there exists a synergistic growth relationship between Mycobacterium tuberculosis and fungal respiratory pathogens among other co-morbidities [5]. The most common respiratory fungal diseases include: candidiasis, aspergillosis, cryptococcosis and mucormycosis [6].

The WHO estimates that more than a million people develop chronic pulmonary aspergillosis after being treated for TB every year [7]. Majority of the cases occur in countries with high burden of TB including Bangladesh, China, India, Indonesia, Philippines and Sub Saharan Africa. Due to fungal diagnostic challenges, almost half of those who develop the disease die within five years [7]. The symptoms of chronic pulmonary aspergillosis (CPA) i.e. weight loss, severe shortness of breath, fatigue and coughing up blood are similar to those of TB that cannot be differentiated clinically. This often leads to misdiagnosis and subsequent inappropriate treatment. Fungal infection can progress undetected for years until it is too late for antifungal intervention [8].

Around one-third of TB patients develop cavities in their lungs, making them vulnerable to infection by air borne fungi that are ubiquitous in the environment [9]. Studies focusing on the global burden of chronic pulmonary aspergillosis have highlighted the importance of following up on TB patients after their initial treatment, and having the right diagnosis available [10]. Chronic pulmonary aspergillosis (CPA) requires long-term antifungal therapy, while some, surgical intervention. Mycological investigation is required to diagnose the disease early to increase the chance of survival [11].

The National Tuberculosis Leprosy and Lung Disease Program (NTLD-P) in Kenya seeks to reduce mortality and morbidity due to chronic lung diseases while promoting lung health in the general population. Currently, there is an increased mortality among tuberculosis patients including those who have successfully completed treatment, due to development of cavitation and bronchiectasis that favors the colonization of filamentous fungi [12]. Therefore, undiagnosed or missed diagnosis of respiratory fungal infection significantly increases the morbidity and mortality despite successful TB treatment [13]. There is limited empirical evidence on the existence and extent of respiratory fungal dis- 
eases and possible co-morbidities with pulmonary TB in Kenya. In light of this inadequate information, the current study sought to isolate and characterize pulmonary fungal pathogens from TB relapse and retreatment cases in Kenya, a Sub-Saharan Africa setting.

\section{Materials and Methods}

\subsection{Sampling Sites}

In the current cross-sectional study, sputum samples were obtained from 340 relapse and retreatment patients in tuberculosis reference facilities including Moi Teaching and Referral Hospital (MTRH) and, Mbagathi County Referral Hospital. A total of 340 sputum samples from the patients were analyzed during the study. The study was nested in the protocol approved by KEMRI Scientific and Ethics Review Unit (SERU) in which patients provided written informed consent to participate in the study. The current study was reviewed and approved by Kenyatta National Hospital/University of Nairobi Ethics Review Committee (KNH/UoN-ERC) (study number P108/02/2018).

\subsection{Sample Size and Participant Selection Criteria}

Tuberculosis relapse and retreatment cases with recurrent symptoms consistent with pulmonary TB despite compliance with first line anti-TB therapy were included in the study. Relapse and retreatment cases with known HIV/TB co-infection were also recruited. Tuberculosis treatment defaulters, newly diagnosed smear positive TB and patients with extensively drug resistant tuberculosis (XDR-TB) as well as extra-pulmonary TB were excluded from the study. The sample size was determined based on country estimated burden (67\%) of chronic pulmonary aspergillosis (CPA) among pulmonary tuberculosis patients [14]. Fischer's et al. (1998) formula with a 95\% confidence level was used, where a minimum of 340 participants was worked out for the study as indicated below.

$$
n=\frac{z_{1-\alpha / 2}^{2} p(1-p)}{d^{2}}
$$

where: $n=$ Sample size

$$
z_{1-\alpha / 2}=1.96
$$

$p=67 \%$ (estimated prevalence of CPA in PTB patients)

$d=$ Absolute precision $(0.05)$

Therefore: $n=\frac{1.96^{2} \times 0.67(1-0.67)}{0.05^{2}}=340$

\subsection{Sputum Sample Processing}

Fresh expectorated morning sputum specimen were collected in sterile sputum mugs and packaged using the triple packaging technique following the requisite biosafety guidelines [15]. The samples were transported to Kenya Medical Research Institute (KEMRI), Centre for Microbiology Research-Mycology Labora- 
tory. Coded samples were first mucolysed with sputasol and inoculated on Sabourauds Dextrose Agar (SDA) in duplicates. The media was supplemented with $10 \mathrm{ml}$ of Chloramphenicol and $0.65 \mathrm{ml}$ Gentamicin $(40 \mathrm{mg} / \mathrm{ml})$ to inhibit bacterial contamination. Sterility check and ability to support the growth fungi was performed on each batch of media and subsequent negative and positive controls were incubated with every batch of cultures. Inoculated plates were incubated at $30^{\circ} \mathrm{C}$ for up to 4 weeks and evaluated daily for fungal growth. Plates that had no growth at the fourth week were deemed negative and disposed appropriately following the laboratory waste disposal procedures.

\subsection{Identification of Fungal Isolates}

Fungi growing on culture were identified by morphologic characteristics using both macroscopic and microscopic and features. Macroscopic features such as colony growth rate, color on the obverse and reverse, elevation, texture and colony size were captured. Specimen for microscopy were prepared using tease-mount technique and stained with lacto-phenol cotton blue as described by Campbell \& Johnson [16]. Microscopic features were observed at $\times 40$ magnification and features including conidia production, shapes and arrangement of phialides were noted to aid in identification of the isolates. Confirmation of the isolates were done using ITS, Calmodulin and beta tubulin gene sequence. This was achieved courtesy of support from Medical Mycology Research Institute-Chiba University-Japan. Manipulation of all live cultures was done under level II containment facilities in compliance with the Mycology Laboratory safety standards and KEMRI biosafety guidelines.

\subsection{Data Analysis}

The isolation frequency of individual mould species was recorded and expressed as percentage of the total number of moulds isolated from the sputum samples analyzed. Pictures of representative fungal species on culture and microscopy were also captured to demonstrate their morphological diversity.

\section{Results}

Diverse filamentous fungi were recovered from sputum samples of the study participants. Out of the 340 sputa analyzed, $16 \%(\mathrm{n}=53)$ were positive for pathogenic filamentous fungi. The genus Aspergillus were the most frequently isolated accounting for 68\% ( $\mathrm{n}=36)$ of the total isolates with Aspergillus flavus and $A$. niger the being most dominant species constituting 23\%, $(\mathrm{n}=12)$ and $15 \%(\mathrm{n}$ $=8)$ respectively. Only $4 \%(\mathrm{n}=2)$ isolates of Aspergilllus candidus were isolated. Other Aspergilli present in the samples were A. fumigatus, A. terreus and $A$. vesiclor. Additionally, Paecillomyces variotii $(9 \%, \mathrm{n}=5)$, Scedosporium aspipermum $(6 \%, \mathrm{n}=3)$, Mucor racemosus $(8 \%, \mathrm{n}=4)$ and Penicillium spp. $(9 \%, \mathrm{n}=$ $5)$ were isolated from the sputum. The frequency, macroscopic and microscopic morphological characteristics of the representative fungi isolated are described in Table 1, with the respective isolates in Plate 1 (a)-(j) subsequently. 
Table 1. The frequency, macroscopic and microscopic features of filamentous fungi from sputum.

\begin{tabular}{|c|c|c|c|c|}
\hline $\begin{array}{l}\text { Name of Isolate } \\
\text { and reference plate }\end{array}$ & $\begin{array}{l}\text { Colony } \\
\text { morphology } \\
\text { (obverse) }\end{array}$ & $\begin{array}{l}\text { Colony } \\
\text { morphology } \\
\text { (reverse) }\end{array}$ & $\begin{array}{l}\text { Structure } \\
\text { of phialides }\end{array}$ & $\begin{array}{c}\text { Frequency } \\
\text { n (\%) }\end{array}$ \\
\hline $\begin{array}{c}\text { Plate (b). } \\
\text { Aspergillus flavus }\end{array}$ & $\begin{array}{l}\text { Light green } \\
\text { powdery } \\
\text { colony }\end{array}$ & Cream-yellow & $\begin{array}{l}\text { Biseriate phialides } \\
\text { and aerial hyphae } \\
\text { with rough, } \\
\text { spiny conidiophores }\end{array}$ & $12(23 \%)$ \\
\hline $\begin{array}{c}\text { Plate (d). } \\
\text { Aspergillus niger }\end{array}$ & $\begin{array}{c}\text { Black with } \\
\text { white margin }\end{array}$ & Cream-white & $\begin{array}{l}\text { Biseriate phialides } \\
\text { covering entire } \\
\text { vesicle forming } \\
\text { radiate head }\end{array}$ & $8(15 \%)$ \\
\hline $\begin{array}{l}\text { Plate (a). } \\
\text { Aspergillus } \\
\text { fumigatus }\end{array}$ & $\begin{array}{l}\text { Velvety, white, } \\
\text { dark greenish }\end{array}$ & Cream white & $\begin{array}{l}\text { Uniseriate phialides } \\
\text { covering upper } \\
\text { two thirds of vesicle. }\end{array}$ & $6(11 \%)$ \\
\hline $\begin{array}{c}\text { Plate }(\mathrm{j}) . \\
\text { Mucor racemosus }\end{array}$ & $\begin{array}{l}\text { White } \\
\text { powdery } \\
\text { colony }\end{array}$ & Cream white & $\begin{array}{l}\text { Aerial hyphae } \\
\text { bearing } \\
\text { conidiophores }\end{array}$ & $4(8 \%)$ \\
\hline $\begin{array}{c}\text { Plate (e). } \\
\text { Aspergillus terreus }\end{array}$ & $\begin{array}{l}\text { Velvety, } \\
\text { cinnamon } \\
\text { brown }\end{array}$ & Whitish brown & $\begin{array}{l}\text { Compact fan-shaped } \\
\text { heads with } \\
\text { metulae, phialides, } \\
\text { and upright } \\
\text { conidiophore }\end{array}$ & $5(9 \%)$ \\
\hline $\begin{array}{c}\text { Plate (f). } \\
\text { Aspergillus candidus }\end{array}$ & White & Orange yellow & $\begin{array}{l}\text { Intact sporing head } \\
\text { with metulae and } \\
\text { phialides, over the } \\
\text { entire vesicle }\end{array}$ & $2(4 \%)$ \\
\hline $\begin{array}{c}\text { Plate (g). } \\
\text { Penicillium spp. }\end{array}$ & $\begin{array}{l}\text { Bluish green, } \\
\text { white margin, } \\
\text { exudates } \\
\text { present, } \\
\text { raised with } \\
\text { radial furrows }\end{array}$ & $\begin{array}{l}\text { Creamish } \\
\text { yellow }\end{array}$ & $\begin{array}{l}\text { Branching, flask } \\
\text { shaped conidiophores } \\
\text { with metulae }\end{array}$ & $5(9 \%)$ \\
\hline $\begin{array}{c}\text { Plate }(\mathrm{i}) . \\
\text { Paecilomyces variotii }\end{array}$ & Yellowish brown & Pale brown & $\begin{array}{l}\text { Long slender } \\
\text { phialides } \\
\text { appearing singly } \\
\text { along hyphae }\end{array}$ & $5(9 \%)$ \\
\hline $\begin{array}{c}\text { Plate (c). } \\
\text { Aspergillus vesicolor }\end{array}$ & $\begin{array}{l}\text { Greenish } \\
\text { yellow }\end{array}$ & Orange yellow & $\begin{array}{c}\text { Biseriate, loosely } \\
\text { radiate } \\
\text { phialides covering } \\
\text { entire vesicle }\end{array}$ & $3(6 \%)$ \\
\hline $\begin{array}{c}\text { Plate (h.) } \\
\text { Scedosporium } \\
\text { aspiospermum }\end{array}$ & $\begin{array}{l}\text { White cottony } \\
\text { aerial mycelia }\end{array}$ & Greyish black & $\begin{array}{c}\text { Septate hyphae } \\
\text { with short } \\
\text { conidiophores } \\
\text { bearing condia singley }\end{array}$ & $3(6 \%)$ \\
\hline $\begin{array}{l}\text { Total number } \\
\text { of isolates }\end{array}$ & & & & $53(16 \%)$ \\
\hline
\end{tabular}




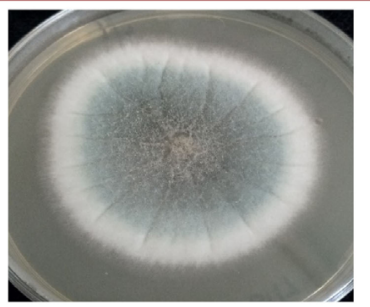

(i) colony surface

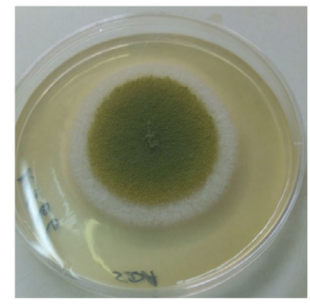

(b)

(i) Colony surface

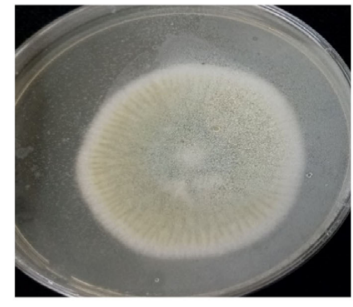

(c)

(i) Colony surface

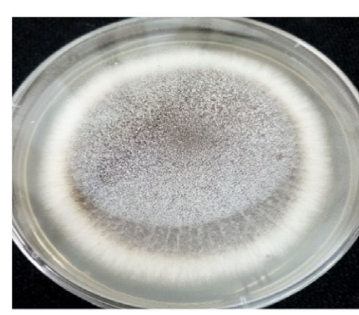

(d)

(i) Colony surface

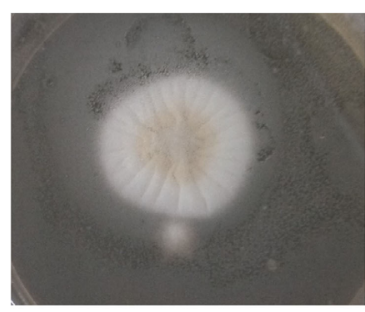

(e)

(i) Colony obverse

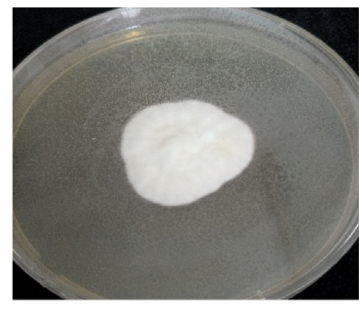

(f)

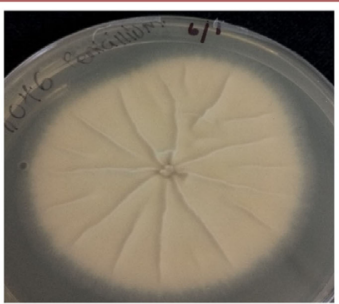

(ii) Reverse

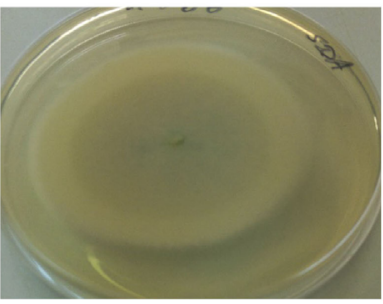

(ii) Reverse

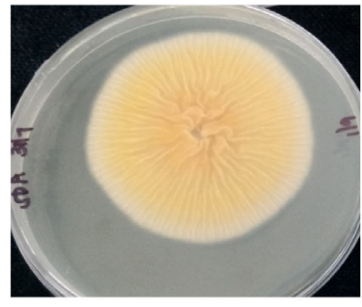

(ii) Reverse

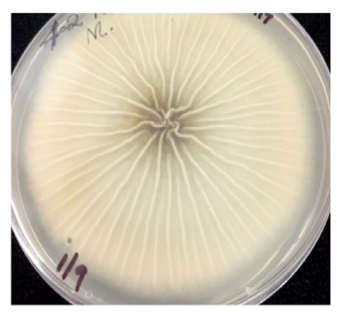

(ii) Reverse

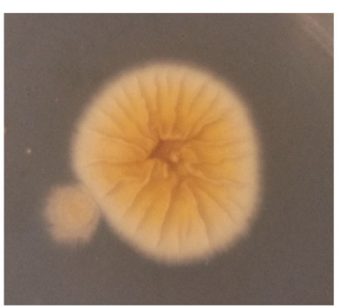

(ii) Reverse

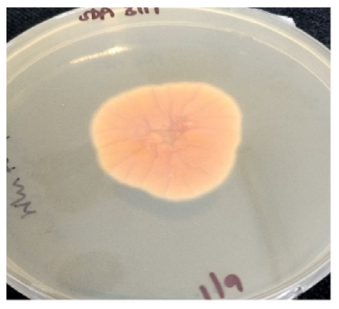

(ii) Reverse

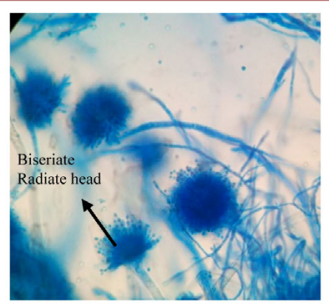

(ii) Microscopic features

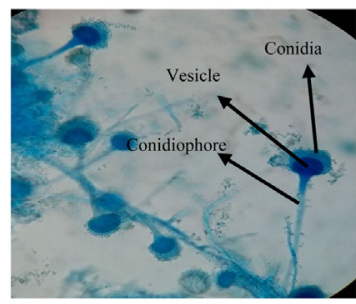

(ii) Microscopic features

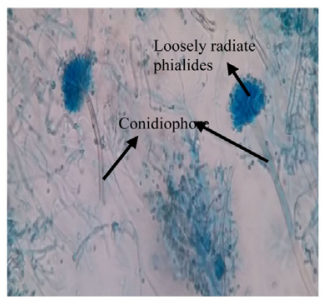

(ii) Microscopic features

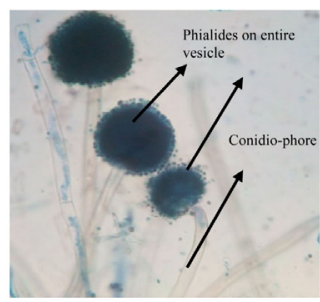

(ii) Microscopic features

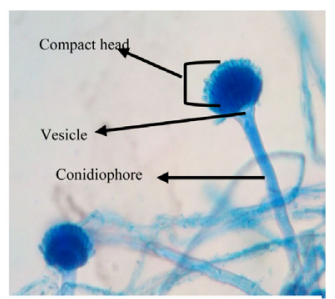

(ii) Microscopic features

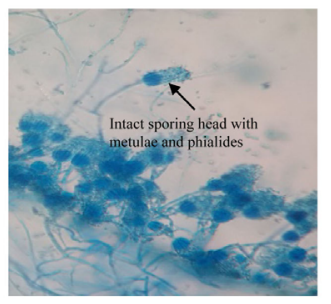

(ii) Microscopic features 


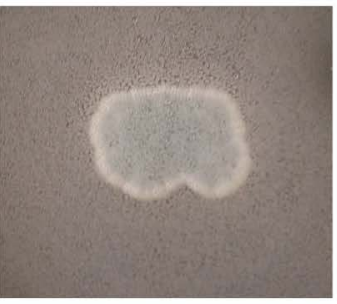

(g)

(i). Colony surface

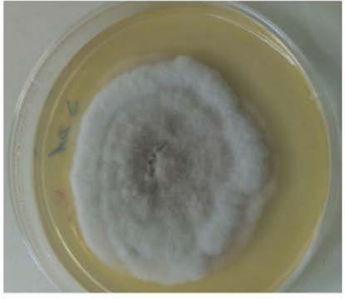

(i) Colony surface

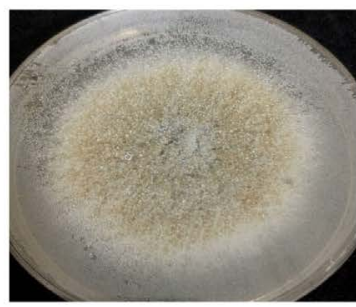

(i)

(i) Colony surface

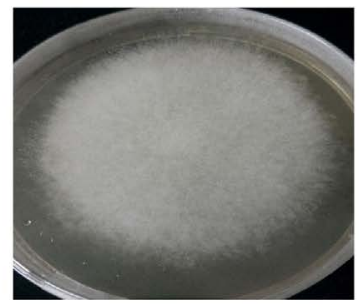

(j)

(i) Colony surface-aerial mycelia

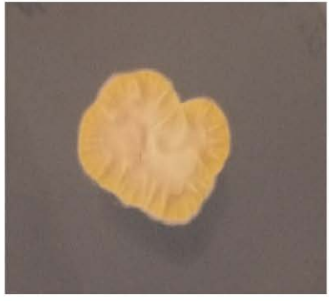

(ii) Reverse

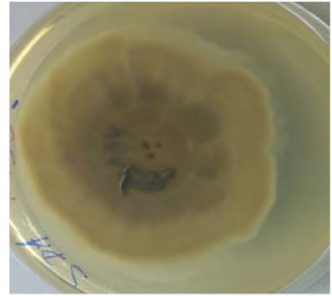

(ii) Reverse

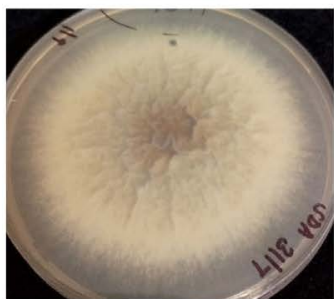

(ii) Reverse

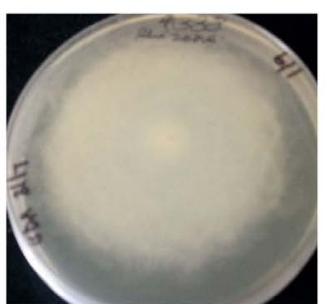

(ii) Reverse

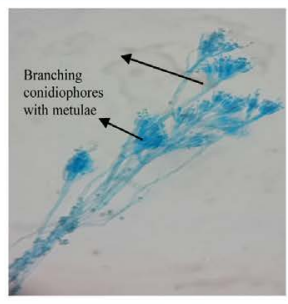

(ii) Microscopic features

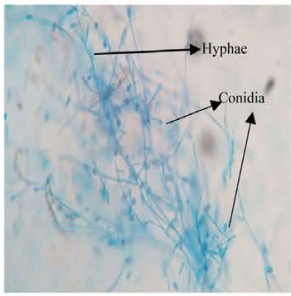

(ii) Microscopic features

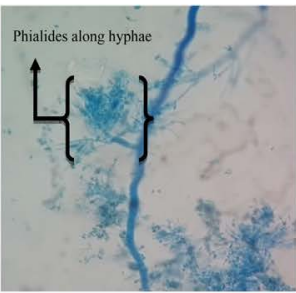

(ii) Microscopic features

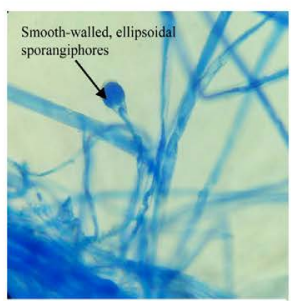

(ii) Microscopic features

Plate 1. (a) Aspergillus fumigatus, (b) Aspergillus flavus, (c) Aspergillus vesicolor, (d) Aspergillus niger, (e) Aspergillus terreus (f) Aspergillus candidus; (g) Penicillium spp. (SDA); (h) Scedosporium aspiospermum; (i) Paecilomyces variotii; (j) Mucor racemosus.

\section{Discussion}

Fungal diseases have emerged as major pathogens among the immunocompromised individuals [17]. The frequency of infections is generally on the rise and appropriate strategies are needed to avert the problem. The current study examined sputa samples from individuals presenting with clinical symptoms typical of pulmonary tuberculosis who had a history of previous treatment for tuberculosis. Out of the 340 samples examined, $16 \%(n=53)$ were positive for a variety of moulds which have been implicated in invasive mycoses and other fungal related illnesses.

The genus Aspergillus was the most frequently isolated fungi among the isolates recovered. Members of the genus Aspergillus are ubiquitous and their 
spores are airborne which can be acquired through inhalation [18]. There are over 200 species of Aspergilli but a few are associated with clinical disease. In the current study, distinct species were isolated among them Aspergillus flavus and A. niger which were the dominant species constituting $23 \%(\mathrm{n}=12)$ and $15 \%(\mathrm{n}$ $=8$ ) respectively. Other Aspergilli included $A$. fumigatus $(11 \%, \mathrm{n}=6)$, A. terreus $(9 \%, \mathrm{n}=5), A$. versicolor $(6 \%, \mathrm{n}=3)$ and $A$. candidus $(4 \%, \mathrm{n}=2)$. Individuals with a debilitated immune system such as those with leukaemia, severe asthma, cystic fibrosis, HIV/AIDS and people with lung injuries including those who have had tuberculosis are at highest risk of infection and disease [19].

Pulmonary fungal infections such as chronic bronchopulmonary aspergillosis (CPA), allergic bronchopulmonary aspergillosis (ABPA) and other fungal lung etiologies can present with clinical symptoms that mimic pulmonary TB [20]. Various diagnostic approaches for pulmonary aspergillosis have been proposed and it has been suggested that the most reliable method is the detection of aspergillus antibody depicting an immunological response to the infection. The positivity rate of sputum samples is known to be low in patients with CPA despite a high number of Aspergillus spp. in the lung cavities [21]. Therefore, the results from sputum cultures in the current study may be lower due to the relatively low sensitivity of sputum fungal culture. However, the findings paint a clear picture of the existing fungal infection among individuals presenting with pulmonary conditions clinically typical of tuberculosis. It depicts the significance of pulmonary fungal colonization that is unattended and being treated as TB leading to disease progression and poor TB treatment outcome due to missed diagnosis. This scenario poses significant challenges and constraints to TB management efforts.

Other studies have demonstrated the existence of Aspergillus spp. in respiratory specimen of patients suspected of TB. In Cameroon, a study carried out to determine the prevalence of respiratory tract aspergillosis in sputum of patients suspected of pulmonary tuberculosis (TB), 30 (15\%) of Aspergillus spp. were isolated from 200 sputa samples with a co-infection with TB in 9 (4.5\%) of the cases [22]. Literature search of all epidemiology papers that reported fungal infections in Kenya revealed that about $7 \%$ of the Kenyan population suffers from a significant fungal infection at any one time. Further, chronic pulmonary aspergillosis (CPA) following TB was reported at a prevalence of 10,848 cases $(32 / 100,000)$. The reported adult asthma prevalence was $3.1 \%$ and it is assumed that $2.5 \%$ have allergic bronchopulmonary aspergillosis implying that 17,696 $(44 / 100,000)$ individuals were affected [14]. The presence of high concentration of fungal spores both in indoor and outdoor environments particularly the $A s$ pegillus spp. acts as a source of most infections and immunosuppression is the major risk factor determining the outcome of the infection and the resulting pathologies [23].

Individuals who are culture positive for diverse Aspergillus species are at highest risk of invasive aspergillosis (IA), allergic-bronchopulmonary aspergillosis (ABPA) and bronchitis [24]. Patients presenting with various clinical 
symptoms such as frequent chest pain, tightness, fatigue, weight loss, productive cough and labored breathing are non-specific for fungal or other lung disorders including tuberculosis. Therefore pulmonary fungal infection may be indistinguishable clinically from other lung etiologies [1]. In Kenya, there is a well-established program for tuberculosis and lung diseases. Nevertheless, considerable efforts and resources have been focused on the diagnosis and management of tuberculosis with minimal attention to possible pulmonary fungal infections which are likely misdiagnosed and treated as relapse and TB culture contaminants.

In the present study, Paecillomyces variotii was isolated in $9 \%(\mathrm{n}=5)$ of the samples. This species represents a noteworthy emerging opportunistic pathogen among the immunocompromised individuals [25]. The fungus has been previously isolated in food products, soil as well as indoor home environments [26]. Further, $P$. variotii has been implicated in pulmonary mycoses in diabetics and cases of endocarditis, sphenoid infections and other related diseases [27] [28] [29]. The isolation of $P$. variotii among tuberculosis retreatment cases in the current study highlights a possible co-infection complicating the treatment of the affected individuals.

Penicillium spp. represents a large group of ubiquitous genus consisting over 350 recognized species [30]. Members of this group are mainly responsible contamination of food products and mycotoxin production. Opportunistic infections attributable to Penicillium spp. have also been reported mainly entailing prosthetic endocarditis, otomycosis as well as pulmonary involvement in immunocompromised individuals [31]. The frequency of isolation of Penicillium spp. from the sputum specimen in the current study was $9 \%$. This shows that the genus could be a significant complication in pulmonary tuberculosis necessitating further in-depth inquiry to elaborate the clinical picture and prognosis.

Scedosporium aspiospermum was isolated from 6\%, of the samples, the fungus is a ubiquitous filamentous mould found in soil and polluted water [32]. The fungus has been implicated in a wide variety of severe infections including, lungs, sinuses, bone and disseminated disease involving the central nervous system among immunocompromised individuals as well as those receiving steroidal medication and such infections are usually fatal [33]. Infection with $S$. aspiospermum has also been reported in immunocompetent individuals signifying the virulence of this species. In the spectrum of infections associated with $S$. aspiospermum, lung infection is fairly overriding and often progressing in patients with prevailing lung conditions and surgical resection is main intervention since $S$. aspiospermum is intrinsically resistant to various antifungals. A greater survival rate in immunocompetent individuals has been noted compared to the immunocompromised [34]. It would be essential to evaluate presumptive tuberculosis relapse and retreatment cases for possible infection and co-infection with pathogenic fungi. These should also include the HIV immunocompromised individuals presenting with severe pulmonary diseases.

Mucor racemosus that was recovered from the sputum of $8 \%$ of the patients is 
a dimorphic fungi belonging to a large group of fungi named the Mucorymycetes collectively responsible for infections referred to as mucorymycoses [35]. Frequent human infections are caused by Rhizopus, Absidia and Mucor as well as Chlamydoconidia species. Mucor is reported as the most common usually acquired through inhalation [36]. The spectrum of disease associated with mucorymycoses includes rhino-cerebral affecting the sinuses and the brain with ensuing fever, sinus congestion and headache. Pulmonary mucormycosis mainly infects the lung resulting to chest pain, breathing problems, cough and fever as well as disseminated infections [37]. Since lung infections with Mucorales present similar clinical picture as tuberculosis or pneumonia, this may be misdiagnosed and the patient put on anti TB medication as the infection progresses. Mucormycoses is now recognized as a neglected tropical disease (NTD) [38].

A significant number of pulmonary tuberculosis patients currently on treatment were diagnosed clinically or were smear negative. It is likely that these individuals could have had pulmonary fungal etiologies. According to Denning (2018), the WHO reported that approximately 2.2 million out of 5.2 million new cases of pulmonary tuberculosis were clinically diagnosed or smear negative in 2015. It has also been observed that there is a low specificity of presumptive TB suggestive X-ray and hence the diagnosis is often inconclusive. The utility of computed tomography (CT) has been evaluated for the diagnosis of filamentous fungi infection among the immunocompromised. In one of the studies, CT-guided lung biopsies showed high diagnostic accuracy comparable to antigen based tests and molecular assays [39]. However, such high tech facilities are often not available in resource constrained countries and if available, they are often not affordable to the common man.

It has been reported that the diagnostic yield of cultures from patients with pulmonary fungal infections particularly those with CPA is usually low, and this could be considered a limitation of the study. Therefore, the burden of fungal infection among the patients examined could be higher and additional microbiological tests on specimen such as broncho-alveolar lavage fluid (BALF) would be invaluable. Nevertheless, positive sputum cultures from patients undergoing treatment for a fungal disease are predictive of treatment response.

\subsection{Conclusion}

The current study highlights the significance of pulmonary fungal infections among presumptive tuberculosis relapse and retreatment patients. Mycological investigation indicates that unlike other studies where Aspergillus fumigatus is the main etiology, other Aspergillus species such as A. flavus and A. niger are involved in Kenya. These species are often intrinsically resistant to triazoles as first line treatment for pulmonary aspergillosis. The other filamentous fungi isolated such as Penicillium spp., Paecillomyces spp., Mucor spp. and Scedosporium spp. are frequently reported as TB culture contaminants but could be of clinical significance. The diagnosis and management of pulmonary fungal infections in Kenya has been hampered by technical and infrastructural inadequacies primarily the lack of 
trained medical mycologists, inadequate laboratory infrastructure for fungal diagnosis and scarcity of effective and affordable antifungal drugs.

\subsection{Recommendation}

Smear negative patients presenting with clinical symptoms of tuberculosis relapse should be subjected to mycological investigations before retreatment. This requires investment in technical and infrastructural capabilities for diagnosis and management of fungal infections.

\section{Acknowledgements}

The authors acknowledge the support for this work granted by Kenya Medical Research Institute (KEMRI). Gratitude also goes to Leah and Judith at the mycology laboratory for the support during data capture.

\section{Conflicts of Interest}

The authors declare no competing interests.

\section{References}

[1] Bongomin, F., Gago, S., Oladele, R.O. and Denning, D.W. (2017) Global and Multi-National Prevalence of Fungal Diseases-Estimate Precision. Journal of Fungi, 3 57. https://doi.org/10.3390/jof3040057

[2] Bansod, S. and Rai, M. (2008) Emerging of Mycotic Infection in Patients Infected with Mycobacterium tuberculosis. World Journal of Medical Sciences, 3, 74-80.

[3] WHO (2015) Use of High Burden Country Lists for TB by WHO in the Post-2015 Era. WHO/HTM/TB/2014.29, WHO Press, Geneva, 19.

[4] Ministry of Health (2016) N-PTP Survey R. Survey Report.

[5] Marais, B.J., Lönnroth, K., Lawn, S.D., Migliori, G.B., Mwaba, P., Glaziou, P., et al. (2013) Tuberculosis Comorbidity with Communicable and Non-Communicable Diseases: Integrating Health Services and Control Efforts. The Lancet Infectious Diseases, 13, 436-448. https://doi.org/10.1016/S1473-3099(13)70015-X

[6] Yahaya, H., Taura, D.W., Aliyu, I.A., Bala, J., Yunusa, I., Ahmad, I.M., et al. (2015) Spectrum of Opportunistic Mould Infections in Suspected Pulmonary Tuberculosis (TB) Patients. International Journal of Microbiology and Application, 2, 5-11. http://www.openscienceonline.com/journal/ijma

[7] World Health Organization (WHO) (2011) Tuberculosis Survivors at Risk of Fungal Infection. http://www.who.int/bulletin/volumes/89/12/11-089441.pdf

[8] Limper, A.H., Knox, K.S., Sarosi, G.A., Ampel, N.M., Bennett, J.E., Catanzaro, A., et al. (2010) American Thoracic Society Documents: An Official American Thoracic Society Statement: Treatment of Fungal Infections in Adult Pulmonary and Critical Care Patients.

http://www.thoracic.org/statements/resources/tb-opi/treatment-of-fungal-infection s-in-adult-pulmonary-critical-care-and-sleep-medicine.pdf

[9] Denning, D.W., Pleuvry, A. and Cole, D.C. (2011) Global Burden of Chronic Pulmonary Aspergillosis as a Sequel to Pulmonary Tuberculosis. Bulletin of the World Health Organization, 89, 864-872. https://doi.org/10.2471/BLT.11.089441 http://www.who.int/bulletin/volumes/89/12/11-089441.pdf 
[10] Suman, S. and Kumar, P. (2016) Prevalence of Mycotic Flora with Pulmonary Tuberculosis Patient in a Tertiary Care Hospital. International Journal of Contemporary Medical Research, 3, 2563-2564. https://doi.org/10.15406/jbmoa.2016.03.00069

[11] Kalyani, C.S., Koripella, R.L. and Madhu, C. (2016) Fungal Isolates in Sputum Samples of Multidrug-Resistant Tuberculosis Suspects. International Journal of Scientific Study, 4, 164-166.

[12] Dhooria, S., Kumar, P., Saikia, B., Aggarwal, A.N., Gupta, D., Behera, D., et al. (2014) Prevalence of Aspergillus Sensitisation in Pulmonary Tuberculosis-Related Fibrocavitary Disease. International Journal of Tuberculosis and Lung Disease, 18, 850-855. https://doi.org/10.5588/ijtld.13.0838

[13] Agarwal, R., Denning, D.W. and Chakrabarti, A. (2014) Estimation of the Burden of Chronic and Allergic Pulmonary Aspergillosis in India. PLOS ONE, 9, e114745. https://doi.org/10.1371/journal.pone.0114745

[14] Guto, J.A., Bii, C.C. and Denning, D.W. (2016) Estimated Burden of Fungal Infections in Kenya. The Journal of Infection in Developing Countries, 10, 777-784. http://www.ncbi.nlm.nih.gov/pubmed/27580321 https://doi.org/10.3855/jidc.7614

[15] Heifets, L. (2014) Mycobacteriology Laboratory. Clinics in Chest Medicine, 18, 35-53. https://doi.org/10.1016/S0272-5231(05)70354-3

[16] Campbell, C.K. and Johnson, E.M. (2013) Identification of Pathogenic Fungi. Blackwell Publishing, Chichester.

[17] Gupte, S. (2015) A Review on Emerging Fungal Infections and Their Significance. Journal of Bacteriology \& Mycology: Open Access, 1, 9-11. https://doi.org/10.15406/jbmoa.2015.01.00009

[18] Ohba, H., Miwa, S., Shirai, M. and Kanai, M. (2012) Clinical Characteristics and Prognosis of Chronic Pulmonary Aspergillosis. Respiratory Medicine, 106, 724-729. https://doi.org/10.1016/j.rmed.2012.01.014

[19] Taccone, F.S., Van den Abeele, A.M., Bulpa, P., Misset, B., Meersseman, W., Cardoso, T., et al. (2015) Epidemiology of Invasive Aspergillosis in Critically Ill Patients: Clinical Presentation, Underlying Conditions, and Outcomes. Critical Care, 19, 1-15. https://doi.org/10.1186/s13054-014-0722-7

[20] Denning, D.W., Cadranel, J., Beigelman-Aubry, C., Ader, F., Chakrabarti, A., Blot, S., et al. (2016) Chronic Pulmonary Aspergillosis: Rationale and Clinical Guidelines for Diagnosis and Management. European Respiratory Journal, 47, 45-68. https://doi.org/10.1183/13993003.00583-2015

[21] Denning, D.W., Page, I.D., Chakaya, J., Jabeen, K., Jude, C.M., Cornet, M., et al. (2018) Case Definition of Chronic Pulmonary Aspergillosis in Resource-Constrained Settings. Emerging Infectious Diseases, 24, e171312. https://doi.org/10.3201/eid2408.171312

[22] Anna, N.L., Anselm, E.A., KLucien-Henri, F., Dickson, N.S., Jules-Clement, A.N., David, N.A., et al. (2012) Respiratory Tract Aspergillosis in the Sputum of Patients Suspected of Tuberculosis in Fako Division-Cameroon. Journal of Microbiology Research, 2, 68-72. https://doi.org/10.5923/j.microbiology.20120204.01

[23] Richardson, M., Bowyer, P. and Sabino, R. (2019) The Human Lung and Aspergillus: You Are What You Breathe in? Medical Mycology, 57, S145-S154. https://doi.org/10.1093/mmy/myy149

[24] Gago, S., Denning, D.W. and Bowyer, P. (2019) Pathophysiological Aspects of Aspergillus Colonization in Disease. Medical Mycology, 57, S219-S227. https://doi.org/10.1093/mmy/myy076 
[25] Houbraken, J., Verweij, P.E., Rijs, A.J.M.M., Borman, A.M. and Samson, R.A. (2010) Identification of Paecilomyces variotii in Clinical Samples and Settings. Journal of Clinical Microbiology, 48, 2754-2761. https://doi.org/10.1128/JCM.00764-10

[26] Lee, T., Grinshpun, S.A., Martuzevicius, D., Adhikari, A., Crawford, C.M. and Reponen, T. (2006) Culturability and Concentration of Indoor and Outdoor Airborne Fungi in Six Single-Family Homes. Atmospheric Environment, 40, 2902-2910. https://doi.org/10.1016/j.atmosenv.2006.01.011

[27] Abolghasemi, S. and Tabarsi, P. (2015) Pulmonary Paecilomyces in a Diabetic Patient. Tanaffos, 14, 268-271.

[28] Bode, R.B., et al. (2015) Paecilomyces variotii: An Unusual Cause of Isolated Sinusitis.

[29] Goldschmidt, R.A. and Victor, T.A. (2016) Infective Endocarditis Caused by Paecilomyces variotii Infective Endocarditis Caused by Paecilomyces variotii.

[30] Visagie, C.M., Houbraken, J., Frisvad, J.C., Hong, S., Klaassen, C.H.W., Perrone, G., et al. (2014) Studies in Mycology. Studies in Mycology, 78, 343-371.

https://doi.org/10.1016/j.simyco.2014.09.001

[31] Lyratzopoulos, G., Ellis, M., Nerringer, R. and Denning, D.W. (2002) Invasive Infection Due to Penicillium Species Other than P. marneffei. Journal of Infection, 45, 184-195. https://doi.org/10.1053/jinf.2002.1056

[32] Nucci, M. and Anaissie, E.J. (2009) Hyalohyphomycosis. In: Anaissie, E.J., McGinnis, M.R. and Pfaller, M.A., Eds, Clinical Mycology (Second Edition), Churchill Livingstone, London, 309-327. https://doi.org/10.1016/B978-1-4160-5680-5.00013-X

[33] Goldman, C., Akiyama, M.J., Torres, J., Louie, E. and Meehan, S.A. (2016) Medical Mycology Case Reports Scedosporium Apiospermum Infections and the Role of Combination Antifungal Therapy and GM-CSF: A Case Report and Review of the Literature. Medical Mycology Case Reports, 11, 40-43.

https://doi.org/10.1016/j.mmcr.2016.04.005

[34] Agatha, D., Krishnan, K.U. and Dillirani, V.S. (2014) Scedosporium spp Lung Infection in Immunocompetent Patients. Indian Journal of Pathology and Microbiology, 57, 635-637. https://doi.org/10.4103/0377-4929.142716

[35] Gomes, M.Z.R., Lewis, R.E., et al. (2011) Mucormycosis Caused by Unusual Mucormycetes, Non-Rhizopus, -Mucor, and -Lichtheimia Species. Clinical Microbiology Reviews, 24, 411-445. https://doi.org/10.1128/CMR.00056-10

[36] Panigrahi, M.K., Manju, R., Kumar, S.V. and Toi, P.C. (2014) Pulmonary Mucormycosis Presenting as Nonresolving Pneumonia in a Patient with Diabetes Mellitus. Respiratory Care, 59, e201-e205. https://doi.org/10.4187/respcare.03205

[37] Hassan, M.I.A. and Voigt, K. (2019) Pathogenicity Patterns of Mucormycosis: Epidemiology, Interaction with Immune Cells and Virulence Factors. Medical Mycology, 57, S245-S256. https://doi.org/10.1093/mmy/myz011

[38] Queiroz-Telles, F., Fahal, A.H., Falci, D.R., Caceres, D.H., Chiller, T. and Pasqualotto, A.C. (2017) Neglected Endemic Mycoses. The Lancet Infectious Diseases, 17, e367-e377. https://doi.org/10.1016/S1473-3099(17)30306-7

[39] Lass-Flörl, C., Aigner, M., Nachbaur, D., Eschertzhuber, S., Bucher, B., Geltner, C., et al. (2017) Diagnosing Filamentous Fungal Infections in Immunocompromised Patients Applying Computed Tomography-Guided Percutaneous Lung Biopsies: A 12-Year Experience. Infection, 45, 867-875.

https://doi.org/10.1007/s15010-017-1072-6 


\section{Abbreviations and Acronyms}

TB-Tuberculosis, KEMRI-Kenya Medical Research Institute, SERU-Scientific and Ethics Review Unit, KNH/UoN ERC-Kenyatta National Hospital/University of Nairobi Ethics Review Committee, Retreatment-any individual with a history of treatment for tuberculosis exhibiting clinical symptoms consistent with pulmonary tuberculosis. Relapse-any patient treated for pulmonary tuberculosis having recurrent symptoms despite compliance with first line anti TB drugs. 